\title{
The Big-Fish-Little-Pond Effect on Mathematics Self Concept of Junior School Students in Academically Selective and Non-Selective Schools
}

\author{
Benson Adesina Adegoke $\mathrm{PhD}$ \\ Institute of Education, University of Ibadan, Nigeria \\ E-mail: doctoradegoke@yahoo.com
}

Received: Feb. 21, 2015 Accepted: April 13, 2015 Published: May 1, 2015

doi:10.5296/jse.v5i2.7121 URL: http://dx.doi.org/10.5296/jse.v5i2.7121

\begin{abstract}
The "Big-Fish-Little-Pond Effect" (BFLPE), an application of social comparison theory of educational settings, posits that a student will have a lower academic self-concept in an academically selective school than in a non-selective school. Several studies have been conducted and results supporting and disagreeing with the theory have been documented. However, most of these studies were conducted in Europe, United States of America (USA), Asia and Australia. Relatively none has been conducted in an African setting and indeed in West Africa. The present study was therefore designed to provide empirical information on the tenability of the hypothesis in African setting. Three hundred and twenty eight Junior Secondary School Two (JSS II) students randomly selected from two schools (one academically selective school $\mathrm{N}=194$ and one non-selective school $\mathrm{N}=124$ ) in Ibadan, Nigeria, participated in the study.

The responses of the students to mathematics self-concept questionnaire and their annual scores in Mathematics in JSS I were analysed using Pearson Correlation Coefficient, One-way Analysis of Variance andtwo-level multi-level models in which students (level 1) were nested within schools (level 2). Results show that there was a positive relationship between individual student's annual score in mathematics and mathematics self-concept. High ability students had higher mathematics self-concept than low ability students. This was observed among the students in both schools. However, the mean score, in mathematics self-concept, of students in academically selective schools was higher than the mean score of students in non-selective schools. The two-level multilevel analyses models showed that individual student achievement in mathematics had positive and statistically significant effect
\end{abstract}




\section{Macrothink}

on mathematics self-concept. This result laid credence on the findings of Marsh and his colleagues. However, school-average achievement in mathematics had non-significant negative effect on mathematics self-concept.

These results show that mathematics self-concept may not be a function of whether the school is academically selective or non-selective. Therefore attending academically selective schoolmay not be detrimental for high ability student if he or she can maintain his or her high ability level.The result of the present study is a challenge to assertions of BFLPE, at least from an African setting.

Keywords: Mathematics self-concept, Mathematics achievement, Academically non-selective schools, Academically selective schools. 


\section{Introduction}

Academically selective schools are characterized by their very strict admissions policy. The admission policy strictly defines a high cut off score in the entrance examination for candidates willing to gain admission into such schools. For example, the cut off score for admission into some of these schools is usually set at about $80 \%$. This means that candidates who failed to score up to $80 \%$ in the entrance examination will not be admitted. This kind of admission policy gives

It is important to note that parents and the society in general believe that children in academically selective schools will receive the best of education. No doubt, the importance of delivering the best education to high-ability students can be argued for on the basis of enriching the intellectual climate of a nation, of strengthening a country's socio-economic fabric, and of cultivating talent in all facets of society. This may account for why many parents struggle to have their children admitted into academically selective schools. However, a growing body of research evidence (e.g. Marsh, 2005; Marsh and Craven, 2006; Marsh \&Hau, 2003; Marsh, Köller, \&Baumert, 2001) suggests that segregation on the basis of academic ability does not create optimum environment in which to educate high-ability students. Herb Marsh and his colleagues, in their studies, show that attending academically selective schools has detrimental effect on students' perceptions of their academic abilities (a construct referred to in literature as academic self-concept).

Academic self-concept is one of the two major domains of the construct self-concept. The other domain is termed non-academic domain. Originally, self-concept was considered to be unidimensional construct. Shavelson, Hubner, and Stanton (1976) theorized that self-concept was multidimensional and hierarchically organized with general self-concept at the apex and then split into academic self-concept (e.g. verbal and science). Marsh and Shavelson (1985) suggested that academic self-concept, being central to educational setting, could be split into two specific domains; that is verbal self-concept and mathematics self-concept.

The importance of self-concept in educational setting cannot be overemphasised. This is because it has been found to influence and influenced by academic performance. Based on reciprocal model, Marsh and Craven (2006) emphasized that academic achievement and academic self-concept are reciprocally related. According to Marsh and Craven (2006), high academic achievement is related to improvements in academic self-concept, and in turn, high academic self-concept is related to improvements in academic achievement. Earlier in a longitudinal study, Marsh and Yeung (1997) assessed the relationship between academic self-concept and academic achievement. They found that prior academic achievement was a statistically significant predictor of subsequent academic self-concept for mathematics, English language and Science. When individual ability was controlled for, they found that prior self-concept was a statistically significant positive predictor of subsequent mathematics achievement.

In addition to being an important outcome variable in educational studies, self-concept is an important mediating construct that facilitates the attainment of other desirable psychological and behavioural outcomes. From a socio-cognition perspective, self-concept is a very 
important variable that makes things happen.According to Marsh and Hau (2003), cognitions such as thinking and feeling positively about oneself have the profound benefits on choice, planning, and subsequent accomplishments. And in factsuch benefits transcend traditional disciplinary barriers and are central to goals in many social policy areas. Generally, individuals in all walks of life are likely to accomplish more if they feel competent in what they do, are self-confident, and feel positively about themselves. In a meta-analytical study, Judge and Bono (2001) showed that components of a positive self-concept constructs were among the best predictors of job performance. Parker (1998) showed that in organizational setting, employees who feel more able to perform particular tasks will actually perform better on these tasks, will persist in the face of adversity and will cope more effectively with change. In sports psychology, Marsh (2002) reported that physical self-concept contributed to the prediction of the performance of elite swimmers at international events beyond what could be explained in terms of their previous performance (person bests and international rankings).

Self-concept is a psychological issue and it falls within characteristics of humans being that can only be objectively self-evaluated by the individual when he or she compares himself or herself with others. Mead (1934) sees the self, "as that which can be an object to itself, is essentially a social structure, and it arises in social experience" (p. 140). The person gets to know himself or herself only through others--that is, he or she cannot experience himself or herself directly as such, "but only indirectly, from the particular standpoints of other individual members of the same social group, or from the generalized standpoint of the social group, as a whole, to which he or she belongs" (p. 138).As a result of this, self-concept cannot be adequately understood if the role of frames of reference is ignored. The same objective characteristics and accomplishments can lead to disparate self-concepts depending on the frames of reference or standards of comparison that individuals use to evaluate themselves.

Social comparison theory (Festinger, 1954) is one approach for studying frame-of-reference effects. Therefore, it provides the theoretical underpinning for the present study.In educational context, Marsh and Parker (1984) proposed the big-fish-little-pond effect (BFLPE) to encapsulate frame-of-reference effects posited in social comparison theory. According to the big-fish-little-pond effect (BFLPE), an individual student's academic self-concept is based partly on his/her academic achievement levels and partly on the average of achievement levels of other students in the same school that he or she attends.

The BFLPE hypothesises that students compare their own academic achievements with the academic achievement of their peers and use this comparisonimpressions as the basis for forming their own academic self-concept. That students compare their academic achievement with those of their peers and make use of this comparison as the basis for forming their own academic self-concept is indeed at the core of Marsh and his colleagues approach to BFLPE. Let us examine the theory of Marsh and Hau (2003) in this simple scenario: Consider a capable student who has been evaluated as a top student throughout his or her primary school education. If the student is accepted into an academically selective secondary school, the student may be average or below average in relation to other students in this school rather than at the top of the class. According to BFLPE, this can have detrimental effects on his or 
her academic self-concept as he or she is no longer a big fish in a small pond (top of the class) but is in large pond full of even larger fish (other students who are even brighter), so that he or she is average or below average in relation to the achievement levels in this new, academically selective secondary school.

An important question at this juncture is: What makes a student who was judged to be of high ability in primary school becomes an average or even below average student when he or she gets to an academically selective school? This is an issue that BFLPE studies have not really attended to. Is it the nature of the school? Is it the fault of the student? Is he or she really interested in the subject being considered? What is his or her attitude to the subject being considered? What are the contributions of the parental and environment factors to developing academic self-concept? Although these issues were important, they have not beenadequately addressed in literature.

As observed by Marsh and Hau (2003), another theoretically important issue with profound educational implications is the extent to which the BFLPEs vary across different individual student achievement levels. The question is: Is the BFLPE limited primarily to the lowest achieving students in academically selective educational settings (i.e. settings in which the average level of achievement is high) or be generalised across the achievement continuum? There is some theoretical and empirical disagreement about this issue. Coleman and Fults (1985), for example, predicted and found that students in the top half of academically selective classes experienced little or no decline in self-concept.Also, in the study, Jackman, Wilson, Seaton and Craven (2011) found no decline in the self-concept of some first year medical students whom they sampled in Australia. In contrast,Espenshage, Hale, and Chung (2005), Marsh and Hau (2003), Marsh (2005), Marsh, Tracey, and Craven (2006) argued that attending selective schools should lead to reduced academic self-concepts for all achievement levels. For example, in their study, Marsh and Hau (2003) found that the BFLPE was clearly evident for students of all achievement levels and that the size of the BFLPE varied only slightly with individual student achievement. The inconsistency in the findings of studies on BFLPE necessitated the present study. Besides, nearly all the available literature on BFLPE emanates from the USA, Europe, Asia, and Australia. There is dearth of literature on BFLPE from African settings and indeed in West Africa. Moreover, in most of the past studies little information was given about the differences in the level of the academic self-concept on the basis of the level of ability of the students. Empirical findings from this study will not only add to the existing literature, but also provide support for one of the sides of the existing argument.

\section{Hypotheses}

On the basis of previous research, this study tested the following three hypotheses.

1. Individual student achievement in mathematics will have significant positive effect on his or her mathematics self-concept.

2. High ability students in each of the contrasting schools setting will have positive and significantly higher mathematics self-concept than their colleagues who are of low ability. 
3. School-average achievement in mathematics will have significant negative effect on students' mathematics self-concept.

\section{Method}

\section{Participants}

Three hundred and twenty-eightJunior Secondary School Two students (JSS II) who were randomly selected from two schools (one academically selective and one non-selective) participated in the study. The two schools were from Ibadan North Local Government Area, Oyo State, Nigeria. From academically selective school 194 (105 boys and 89 girls) students and from non-selective school124 (71 boys and 53 girls) participated in the study. The average age of the students ranged between 12 and 14 years $($ Mean $=12.2$ years; Standard Deviation $=1.6$ ).

\section{Materials}

The Mathematics Self-Description Questionnaire (MSDQ) was constructed specifically to measure mathematics self-concept of the students. It consisted of two sections: A and B. Section A solicited information about student's gender, age, and the profession the student wishes to pursue in adult life. The students were also asked to state their scores in Mathematics in the last three examinations they took in their schools.

Section B consisted of 10 items. The reliability of the 10 items was 0.78 (using Cronbach $\alpha$ method). Examples of the items contained in the test were: When compared with my classmates, "I think I am one of the best students in Math"; "I feel that I am among the bottom 5\% of my class" (Appendix 1).The items were placed under 4-point Likert response format of Very true of me (VT); True of me (T); Not True of me (NT); and Very Untrue of Me (VUT). Positively stated items were rated as 4, 3, 2, 1, while scoring was reversed for negatively stated items. The maximum score obtainable was 40 (very high math self-concept) while the minimum obtainable was 10 (very low math self-concept). The MSDQ was administered during mathematics periods in all the classes that were sampled. It took the students, on the average, about 18 minutes to complete the questionnaire.

\section{Mathematics achievement Scores}

The mathematics teachers in each school submitted their marks books. The scores of the students in mathematics were copied from these marks books. It is quite interesting to note that about $93.7 \%$ of the students were found to be very truthful about their scores in math. They did not inflate their scores. Eachstudent's annual score in mathematics was taken as his or her achievement in mathematics. In each school, each student's annual score was standardized (z-score) to have a mean of zero and standard deviation of 1 . These scores were then converted to T-score $(10 z+50)$ scores. This was to avoid negatives and make all the mathematics scores to be in the same metrics. Each school-average in mathematics score was taken as the school-average achievement.

\section{Statistical Analysis}


In this study, individual student raw score in mathematics self-concept was the main outcome variable, while the predictor variables were individual student achievement in mathematics and school-average achievement in mathematics. For data analysis, Pearson correlation coefficient, One-way ANOVA and two models of two-level multilevel analysis procedures were adopted. For the two-level multilevel model adopted, students (level 1) were nested within schools (level 2). In general it is inappropriate to pool responses of individual students without regard to school unless it can be shown that schools do not differ significantly from each other. No doubt there are systematic differences among the four schools used in this study.

Although the same mathematics curriculum is being implemented in each of the contrasting schools, the settings in each of the schools are different. For example, the academically selective school was fee paying school, whereas the non-academically selective school was not a fee paying school. Moreover, in academically selective school, the teacher-pupil ratio was 30:1, while in the non-academically selective schools, the teacher-pupils ratio was approximately 50:1. Most of the classrooms in the non-academically selective schools were characterized by large teacher-pupils ratio. In academically selective schools, there were more trained mathematics teachers than in non-selective school.

Although statistical procedures such Pearson correlation coefficient and ANOVA were used to test differences in the relationship between individual student's self-concept and achievement in mathematics, a two-level multilevel model in which students (level 1) were nested within schools (level 2) was also adopted. Multi-level provides a much richer and more appropriate approach to test the theoretical predictions that would be possible with traditional single-level approaches that ignore the fact that students are clustered within schools (Raudenbush \& Bryk, 2005). This allowed the partitioning of the variance associated with different effects into components associated with individual student (level 1) and the school (level 2). In the present study, multi-level analyses conducted with MULTILEV procedure of LISREL Version 8 (Linear Structural Relations, Jöreskog \& Sörbom 1993) were used to relate individual student achievement and school-average achievement to student mathematics self-concept.The limited number of schools used dictated the use of LISREL. Although the use of Hierarchical Linear and Non-Modell (HLM, Raudenbush, Bryk, \&Congdon, 2005) was tried, poor results were given.For example the results of random effects could not be adequately computed using HLM

A multi-level regression equation comprises a fixed and a random component. In the present study, the fixed component consisted of individual achievement in mathematics, school-average achievement and a constant. The random part consisted of the intercepts of the levels used in the model, namely the school and student levels. These intercepts demonstrated how much the intercepts of the regression equations varied between schools and between students, respectively. 
Analyses of the data were in three stages.

\section{Stage One}

In stage one, in each of the schools, relationship between individual student annual scores in mathematics and in mathematics self-concept was determined. In this stage, Pearson Correlation Coefficient was used

\section{Stage Two}

In stage two, individual student score in mathematics was used to classify him or her as being of high-ability, moderate-ability or low-ability. Using this method, I was able to determine the extent to which students' ability level relate with self-concept. In this stage One-Way ANOVA was used.

\section{Stage Three}

In this stage, multilevel analysis was adopted.

\section{Results}

Results are presented in the order in which the hypotheses were stated.

Hypothesis One: Individual student achievement in mathematics will have significant positive effect on his or her mathematics self-concept.

Table 1 present the relationship between individual student annual scores in mathematics and in mathematics self-concept in both academically selective school and non-selective schools respectively.

Table 1. Relationship between Mathematics Achievement and Mathematics Self-concept.

\begin{tabular}{lll}
\hline & Selective School & Non-Selective school \\
\hline & Mathematics Self-concept & Mathematics Self-concept \\
Mathematics Achievement & $0.325^{*}$ & $0.428^{*}$ \\
\hline
\end{tabular}

*Significant at $\mathrm{p}<0.05$

From table 1, there was a positive and statistically significant relationship between students' achievement in mathematics and mathematics self-concept. However, the relationship between individual student achievement and mathematic self-concept is higher in non-selective school than in selective school. This result confirms the hypothesis that individual student achievement will have significant positive effect on his or her academic self-concept.

Hypothesis Two: High ability students in both selective and non-selective schools will have positive and significantly higher mathematics self-concept than their colleagues who are of 
low ability. This hypothesis was tested separately in each school. This was to determine the extent to which levels of mathematics ability affects mathematics self-concept.

To test this hypothesis One-way Analysis of Variance was conducted. Tables 2 and 3 show the results in academically selective and academically non-selective schools respectively. The results show that the more academically inclined a student is, the more his or her self-concept will be. In academically selective school, students who were classified as being high had highest mean score in mathematics self-concept. The observed mean differences were statistically significant $\mathrm{F}(2,191)=11.98, \mathrm{p}<0.05$

Table 2. Levels of Mathematics Achievement and Mathematics Self-concept in Academically Selective Schools

\begin{tabular}{lccccc}
\hline Level of Achievement $N$ & Mean & SD & \multicolumn{2}{l}{$95 \%$ Confidence Interval } \\
& & & & Lower Bound & Upper Bound \\
\hline Low & 60 & 28.52 & 3.75 & 27.55 & 29.49 \\
Moderate & 72 & 28.79 & 4.51 & 27.73 & 29.85 \\
High & 62 & 31.85 & 4.37 & 30.75 & 32.97 \\
\hline
\end{tabular}

Also as shown in Table 3, among academically non-selective schools, students classified as being high in mathematics achievement had the highest mean score in self-concept than their colleagues who were classified as average or below average. The observed mean differences among the three groups were statistically significant $\mathrm{F}(2,131)=12.10, \mathrm{p}<0.05$.

Table 3. Students Mean Score in Self-concept and levels of Mathematics Achievementin Academically non-selective Schools

\begin{tabular}{|c|c|c|c|c|c|}
\hline \multirow[t]{2}{*}{ Level of Achievement } & \multirow[t]{2}{*}{$\mathrm{N}$} & \multirow[t]{2}{*}{ Mean } & \multirow[t]{2}{*}{ SD } & \multicolumn{2}{|c|}{$95 \%$ Confidence Interval } \\
\hline & & & & Lower Bound & Upper Bound \\
\hline Low & 43 & 23.37 & 2.78 & 22.52 & 24.23 \\
\hline Moderate & 45 & 24.29 & 3.65 & 23.19 & 25.39 \\
\hline High & 46 & 26.78 & 3.66 & 25.69 & 27.87 \\
\hline
\end{tabular}

From the results it can be hypothesized that students who continue to maintain high-ability status are likely to continue to have positive self-concept, while those who cannot maintain 
their high academic ability are likely to have low self-concept.This observation is general to both selective and non-selective schools. These results are in agreement with earlier findings (e.g. Guay, Marsh, \&Bolvin, 2003; Marsh \& Craven, 2003) which showed that higher ability level is related to high self-concept.

Hypothesis Three: School-average achievement in mathematics will have significant negative effect on students' mathematics self-concept.

To test this hypothesis, MULTILEV Procedure of LISREL was used. Two models were examined. The first was variance decomposition model with random intercepts (Usually referred to as Null Model - Kreft\& De Leeuw, 2000). This model served as preliminary step in a multilevel analysis as it provides important information about the outcome (i.e. mathematics self-concept) variability at each levels of the hierarchy. This model also gives the intra-class correlation.

From the results in the random part of the model, the "between group variability" [level 2 Tau-Hat $\left(\widehat{\Phi}_{2}\right)$ is 5.734], while the "within group variability" [level 1Tau-Hat ( $\left.\widehat{\Phi}_{1}\right)$ is 17.377]. An estimate of the level-2 effect (differences between the academically selective and non-selective schools) is obtained as

$$
\frac{5.734}{5.734+17.377}=0.248 \text {. }
$$

The value of 0.248 also gives the intra-class correlation. This indicates that about $24.8 \%$ of the total variation in the students' mathematics self-concept is explained by the differences between schools.

The second model is the typical linear growth model with random intercepts and slopes. Table 4 gives the results of the analyses. As seen in Table 4, in the fixed part of the model, individual student achievement in mathematics was a significant positive predictor of mathematics self-concept $\left(0.139^{*}\right)$. However, the effect of school-average achievement on math self-concept was negative and not statistically significant. This result is not in agreement with the studies of Marsh and his colleagues (e.g. Marsh \&Hau, 2003) who found out that controlling for academic ability, students in academically selective schools had lower math self-concept than able students in low ability schools. In the present study, though a negative relationship between school-average mathematics achievement and mathematics self-concept was obtained, the observed relationship was not statistically significant. 
Table 4. Results of Linear Growth Model with Random and Slopes

Fixed Part of the Model

\begin{tabular}{|c|c|c|c|c|}
\hline Coefficients & Tau-Hat & Std. Error & z-value & $\operatorname{Pr}>z$ \\
\hline Intercept & 20.736 & 3.112 & 6.663 & 0.000 \\
\hline $\begin{array}{l}\text { Individual } \\
\text { Student score }\end{array}$ & 0.139 & 0.020 & 6.993 & 0.000 \\
\hline $\begin{array}{l}\text { School-average } \\
\text { Score }\end{array}$ & -0.005 & 0.080 & -0.064 & 0.949 \\
\hline Deviance $-2 * \log$ & (Likelihoc & 6.450 & & \\
\hline \multicolumn{5}{|c|}{ Random Part of the Model } \\
\hline & Tau-Hat & Std. Error & z-value & $\operatorname{Pr}>z$ \\
\hline \multicolumn{5}{|c|}{ Level 2} \\
\hline Intercept/Intercept & 0.000 & 0.000 & 0.000 & 0.000 \\
\hline $\begin{array}{l}\text { School-average } \\
\text { score }\end{array}$ & -0.003 & 0.084 & -0.034 & 0.973 \\
\hline Schl-Av/Sch-Av & 0.000 & 0.004 & 0.016 & 0.987 \\
\hline \multicolumn{5}{|c|}{ Level 1} \\
\hline Intercept/Intercept & 15.115 & 1. 184 & 12.767 & 0.000 \\
\hline
\end{tabular}

Sch-Av $=$ School-average score

\section{Discussion}

In this study, it was found that there was a positive and statistically significant relationship between students' achievement in mathematics and mathematics self-concept. The results of this study laid credence on the past findings (e.g. Marsh \& Hau, 2003; Marsh, 2005; Liu, Wang\& Perkins, 2008) that high academic ability is related to positive academic self-concept. The results of the bivariate results show that truly, academic self-concept can influence and also be influenced by students' academic performance. This link can be based on the idea that individuals are likely to accomplish more if they feel more competent, have high self-confidence and have more positive perceptions of themselves (Marsh \& Craven, 2006; Tan \& Yates, 2007).

Based on a reciprocal model, Marsh and Craven (2006) emphasized that academic achievement are reciprocally related. According to Marsh and Craven (2006), high academic achievement is related to improvements in academic self-concept, and in turn, high academic 
self-concept is related to improvements in academic achievement. Earlier studies (such as in Marsh \& Yeung 1997), in which the relationships between academic self-concept and academic achievement were assessed, prior academic achievement was a statistically significant predictor of subsequent academic self-concept for mathematics, English language and Science. When individual ability was controlled for, prior self-concept was a statistically significant positive predictor of subsequent mathematics achievement. This may account for the positive relationship between mathematics achievement and mathematics self-concept.

Results of the present study show that mathematical ability has a direct and positive relationship with mathematics self-concept, such that students classified as high ability had higher mean score in mathematics self-concept than their colleagues who were classified as moderate and low ability groups. Two issues arise here and they are: Do students who were judged to be of high ability in their primary schools continue to maintain that high ability status in secondary school? And if some of them do not, then what happens to their self-concept? If a a pupil who was judged to be of high ability in primary school suddenly jumps down to become either average or below average pupil when he or she gets to secondary school, then one expects that his or her self-concept should to become lower. Based on reciprocal model (Marsh and Craven, 2006) below-average level in academic work will bring about lower self-concept. However, that scenario can happen in both academically selective and non-selective schools. It is therefore worthy to note that the type of school that a student attends may not necessarily be related to his or her academic self-concept. This may be the reason for non-significant negative value obtained for the relationship between school-average achievement and mathematics self-concept in the two-level multilevel analyses conducted.

The other issue pertains to what can make a supposed high ability student suddenly become average or even below average ability student. There are many possible reasons for this. One, the student may not be very interested in the subject (e.g. mathematics), the parents may no longer be involved in the child's education as they used to when he or she was in primary school. This may also contribute to his or her upward or down trends in mathematics achievement and mathematics self-concept. In order words mathematics self-concept may not be a function of whether the school is academically selective or non-selective. Mathematics self-concept may after all be a function of ability.

The major strength of this study is in being the first of its kind to examine the BFLPE in a West African setting. In doing so, it is the first step in extending the BFLPE from European setting into West African setting. Unfortunately, however, this study was based on a small sample of academically selective and non-selective schools. No doubt, this has implication on generalizability of the findings. Nevertheless, the differences between the two schools are very obvious, in terms of teacher-student ratio, class size, environment and type of students that attend each school. One would have expected a very glaring BFLPE in the mathematics self-concept of the students. This was not the case. In conclusion, BFLPE could not be established in this study. Further studies that will incorporate more academically selective and non-selective schools are recommended. 


\section{References}

Coleman, J. M., \& Fults, B. A. (1985). Special class placement, level of intelligence, and the self-concept of gifted children: A social comparison perspective. Remedial and Special Education, 6, 7-11. http://dx.doi.org/10.1177/074193258500600103

Espenshade, T., Hale, L., \& Chung, C. (2006). The frog pond revisited: High school academic context, class rank, and elite college admission. Sociology of Education, 78, 269-293. http://dx.doi.org/10.1177/003804070507800401

Festinger, L. (1954). A theory of social comparison processes. Human Relations, 7, 117-140. http://dx.doi.org/10.1177/001872675400700202

Guay, F., Marsh, H., \& Bolvin, M. (2003). Academic self-concept and academic achievement: Development perspectives on their causal ordering. Journal of Educational Psychology, 95(1) 24-36. http://dx.doi.org/10.1037/0022-0663.95.1.124

Jackman, K., Wilson, I. G., Seaton, M., \& Craven, R. G. (2011). Big fish in a big pond: A study of academic self-concept in first year medical students. BMC Medical Education, 11(48). http://dx.doi.org/10.1186/1472-6920-11-48

Jöreskog, K. G., \& Sörbom, D. (1993).LISREL-8 Structural equation modeling with simple command language. Mahwah NJ: Lawrence Erlbaum.

Judge, T. A., \& Bono, J. E. (2001). Relationship of core self-evaluation traits, self-esteem, generalized self-efficacy, locus of control, and emotional stability-with job satisfaction and job performance: A meta-analysis. Journal of Applied Psychology, 86, 80-92. http://dx.doi.org/10.1037/0021-9010.86.1.80

Kreet, I., \& De Leeuw, J. (2000).Introducing multilevel modeling. London: Sage Publications Liu, W., Wang, C. D. J \& Perkins, E. J. (2008). Academic self-concept: A cross-sectional study of grade and gender differences in a Singapore secondary school. Asia Pacific Education Review, 6(1), 20-27. http://dx.doi.org/10.1007/BF03024964

Marsh, H. W. (2002). A multidimensional physical self-concept: A construct validity approach to theory, measurement, and research. Psychology: The Journal of the Hellenic Psychological Society, 9, 459-493.

Marsh, H. W. (2005). Big-fish-little-pond-effect on academic self-concept.German Journal of Educational Psychology, 19, 119-127. http://dx.doi.org/10.1024/1010-0652.19.3.119

Marsh, H. W., \& Craven, R. (2006). Reciprocal effects of self-concept and performance from a multidimensional perspective: Beyond seductive pleasure and unidimensional perspectives. Perspectives on Psychological Science, $\quad 1(2), \quad 33-63$. http://dx.doi.org/10.1111/j.1745-6916.2006.00010.x

Marsh, H. W., \& Hau, K. (2003).Big-fish-little-pond-effect on academic self-concept.A crosscultural (26) country) test of the negative effects of academically selective schools. American Psychologist, 58(5), 364-376. http://dx.doi.org/10.1037/0003-066X.58.5.364 
Marsh, H. W., \& Parker, J. W. (1984). Determinants of student self-concept: Is it better to be a relatively large fish in a small pond even if you don't learn how to swim as well? Journal of $\begin{array}{lrrr}\text { Personality and Social } \quad \text { Psychology, 213-231. } & \text { 47(1), }\end{array}$ http://dx.doi.org/10.1037/0022-3514.47.1.213

Marsh, H. W., \&Yeung, A. S. (1997). Coursework selection: Relations to academic self-concept and achievement. American Educational Research Journal, 34, 691-720. http://dx.doi.org/10.3102/00028312034004691

Marsh, H. W., Koller, O., Baumert, J. (2001). Reunification of East and West German school system.Longitudinal multilevel modeling study of the big-fish-little-pond effect on academic self-concept.American Educational Research Journal, 38(2), 321-350. http://dx.doi.org/10.3102/00028312038002321

Marsh, H. W., Tracey, D. K., \& Craven, R. G. (2006). Multidimensional self-concept structure for preadolescents with mild intellectual disabilities: A hybrid multigroup-mimic approach to factorial invariance and latent mean differences. Educational and Psychological Measurements, 66, 795-818. http://dx.doi.org/10.1177/0013164405285910

Marsh, H., Hey, J. Roche, L. \& Perry, C. (1997). Structure of physical self-concept: Elite athletes and physical education students. Journal of Educational Psychology, 89(2), 369-380. http://dx.doi.org/10.1037/0022-0663.89.2.369

Mead, G. H. (1934). Mind, self, and society.(Vol. 1). Chicago: University of Chicago Press.

Parker, S. K. (1998).Enhancing role breadth self-efficacy: The roles of job enrichment and other organizational interventions.Journal of Applied Psychology, 83, 835-852. http://dx.doi.org/10.1037/0021-9010.83.6.835

Raudenbush, S. W., Bryk, A. S., \& Congdon, R. (2005) HLM6: Hierarchical linear \& nonlinear modeling. Scientific Software International.

Shavelson, R., Hubner, J., \& Stanton, G. (1976) Self-concept: Validation of construct Interpretations. Review of Educational Research, 46(3), 407-421. http://dx.doi.org/10.3102/00346543046003407

Tan, J. B. Y., \& Yates, S. M. (2007).A Rasch analysis of the academic self-concept questionnaire. International Education Journal, 8(2), 470-484.

\section{Appendix 1. Institute of Education}

\section{UNIVERSITY OF IBADAN, IBADAN}

\section{Mathematics Self-Description Questionnaire (MSDQ)}

\section{Introduction}

This questionnaire was developed for the purpose of assessing the extent to which you believe you are better or worse than your classmates in math. Your candid responses will be highly appreciated. However, information you give will be treated with highest confidentiality. It is for research purposes only. 


\section{Demographic Section}

Name:

Age at 01 January, 2015

Sex: Male

Female

(Place a tick where appropriate)

Type of School: Public

Private.

(Place a tick where appropriate)

What were your scores in math in the three examinations (in JS1)? A...B..........

What profession do you want to pursue in life?:

\section{Content Section}

In the table below are the items developed to assess the extent to which you believe you are better than your colleagues in Math. To each item are four options: VT if the statement is very true about you; $\mathbf{T}$ if the statement is true about you, NT if the statement is not true about you; VUT if the statement is very untrue about you. Place a tick in the box that corresponds with what you believe.

\begin{tabular}{|c|c|c|c|c|c|}
\hline $\mathbf{S} / \mathbf{N}$ & When compared with my classmates: & VT & $\mathbf{T}$ & NT & VUT \\
\hline 1 & I think I am one of the best students in math & & & & \\
\hline 2 & I think most of my classmates are smarter than I do & & & & \\
\hline 3 & I participate more than my classmates during math class & & & & \\
\hline 4 & I feel that I am among the bottom $5 \%$ of my class & & & & \\
\hline 5 & I can solve more math problems than my classmates & & & & \\
\hline 6 & $\begin{array}{l}\text { I ask for help with my math assignments more than any of my } \\
\text { classmates }\end{array}$ & & & & \\
\hline 7 & $\begin{array}{l}\text { My teacher calls my name more often than other students during } \\
\text { math class }\end{array}$ & & & & \\
\hline 8 & $\begin{array}{l}\text { I contribute more than my colleagues during discussions in math } \\
\text { class }\end{array}$ & & & & \\
\hline 9 & I find math easier than many of my classmates & & & & \\
\hline 10 & I feel my classmates are doing better than I do in math & & & & \\
\hline
\end{tabular}

